\title{
Alejo Carpentier, the Lost Steps. Art between Nature and Culture
}

\section{Rodica Grigore ${ }^{1}$}

Considered almost unanimously Alejo Carpentier's masterpiece and also one of the most important Latin American literary works of the last century, The Lost Steps (Los pasos perdidos), the novel published in 1953 by the Cuban writer, is a complex book, needing a larger context of interpretation. The text implies an original dealing with the Faustian myth, as far as its narrator intends to be able to change the modern music and to affirm his creative talent. Nevertheless, the journey he takes in the heart of the jungle is also an initiatory road, meant to recover his true identity and to help him understand for the first time the world around. Based on a subtle comparison between the spiritual values of the Western world and the South American one, this novel stands for an exquisite expression of Carpentier's preoccupation with the aesthetics of his time and with the ideology of marvelous real, the artistic orientation he himself established through several of his essays or theoretical works. [Article copies available for a fee from The Transformative Studies Institute. E-mail address: journal@transformativestudies.org Website: http://www.transformativestudies.org (O2019 by The Transformative Studies Institute. All rights reserved.]

KEYWORDS: Modernism, Postmodernism, Marvelous Real, Initiatory Journey, Music, Latin American Novel.

\section{MUSIC AND MODERNITY}

The Lost Steps (Los pasos perdidos 1953) by Alejo Carpentier is almost unanimously considered the Cuban writer's masterpiece as well as one of the most important Latin American literary works of the last century. Interpretations of the novel have tended to consider the cultural context of South American and its social evolution, or artistic trends of the 50s or 60 s. Some readers sought to perceive in this book a definite existentialist influence while some others were fascinated by the protagonist's sense of

\footnotetext{
${ }^{1}$ Rodica Grigore, Ph.D. Biography available at end of article. Address correspondence to: Rodica Grigore; e-mail: rodica.grigore@gmail.com.
} 